\title{
Low-Pt NiNC-supported PtNi nanoalloy oxygen reduction reaction electrocatalysts-In situ tracking of the atomic alloying process
}

Quanchen Feng ( $\nabla$ quanchen.feng@campus.tu-berlin.de)

Technical University of Berlin https://orcid.org/0000-0003-1966-9495

\section{Xingli Wang}

Technical University of Berlin https://orcid.org/0000-0003-2785-9707

\section{Malte Klingenhof}

Technical University of Berlin

\section{Marc Heggen}

Ernst Ruska Centre

\section{Peter Strasser}

Technical University of Berlin https://orcid.org/0000-0002-3884-436X

\section{Article}

Keywords: atomic alloying, oxygen reduction reaction, $\mathrm{PtNi}$, fuel cell devices

Posted Date: November 18th, 2021

DOI: https://doi.org/10.21203/rs.3.rs-1067403/v1

License: (9) This work is licensed under a Creative Commons Attribution 4.0 International License. Read Full License 


\section{Abstract}

Carbon-supported platinum-nickel (Pt-Ni) alloy nanoparticles (NPs) emerge as the electrocatalysts of choice for deployment in polymer electrolyte membrane fuel cell (PEMFC) cathodes. To date, viable PtNi nanoalloy catalysts are characterized by large Pt weight loading of up to $50 \mathrm{wt} \%$. To a large extent, their preparation processes often involve the use of expensive or even hazardous organometallic metal precursors, solvents and capping agents, substantially limiting their synthetic scalability and sustainability. Here, we report a novel synthetic strategy toward highly active low-Pt loaded PtNi nanoalloy Oxygen Reduction Reaction (ORR) catalysts. The synthesis involves the Pyrolysis and Leaching of Ni-organic polymers, subsequent Pt nanoparticle Deposition followed by thermal Alloying (referred to as PLDA) to prepare single Ni atom site (NiNC)-supported bimetallic PtNi nanoalloy electrocatalysts with very low Pt weight contents of 3-5 wt\% Pt loading. We demonstrate that despite this low Pt weight loading, the catalysts exhibit more favorable Pt-mass activities compared to

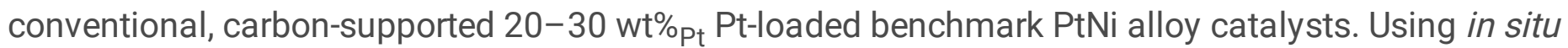
transmission electron microscopy, cyclic voltammetry, and surface CO stripping techniques, we track and unravel the key stages of the formation process of the PtNi nanoparticle catalysts directly at the atomic scale. By carefully chosen reference experiments, we find that carbon-encapsulated Ni NPs, rather than $\mathrm{NiN}_{\mathrm{x}}$ single sites, serve exclusively as the $\mathrm{Ni}$ atom source for PtNi alloy formation during thermal treatments. Our materials concepts offer a pathway to further decrease the overall Pt content of PEM fuel cell devices.

\section{Background}

Hydrogen-fueled polymer electrolyte membrane fuel cells (PEMFC) that generate electricity through the electrochemical oxidation of hydrogen, are an important component in the suite of emerging green and sustainable technology solutions to the looming global energy crisis. ${ }^{1-12}$ The kinetically sluggish oxygen reduction reaction (ORR) at PEMFC cathodes, however, continues to limit the overall PEMFC performance, causes large kinetic overpotentials, and still requires unacceptably high Pt loadings in the cathode catalyst layer. ${ }^{1,13-16}$ Therefore, enormous research efforts have been put into the development of low-Pt content cathode electrocatalysts and layers thereof. This has resulted in a number of new active and lowPt content cathode catalyst design concepts that meet and, in some cases, even exceed current technological Pt ORR mass activity targets. $5,7,9,17-29$

Among these catalyst design concepts, there is a hybrid catalyst design that combines platinum-group metal (PGM)-free transition metal (M)- and nitrogen-doped carbon (MNC) material-an alternative to conventional carbon supports-together with Pt-based nanoparticles (NPs). Following this concept, the drawbacks inherent in both MNC and Pt could be reciprocally offset.

On one hand, the presence of Pt could help to solve the critical stability issues encountered by MNC materials with single $\mathrm{M}-\mathrm{N}_{\mathrm{x}}$ active sites. Jaouen et al improved the stability of FeNC material through the incorporation of minute amounts (1-2 wt\%) of Pt into FeNC. ${ }^{30-32}$ Subjecting this Pt/FeNC hybrid catalyst 
to reductive annealing treatment led to the formation of $\mathrm{Pt} @ \mathrm{FeO}_{\mathrm{x}}$ core-shell structure, which resulted from the migration of some Fe from FeNC support to Pt surface. While this ORR-inactive Pt@FeO $\mathrm{O}_{\mathrm{x}}$ structure did not directly contribute to the overall ORR activity, it still stabilized the FeNC catalyst by suppressing the formation of by-product $\mathrm{H}_{2} \mathrm{O}_{2}$ and reactive oxygen species, which were known to be responsible for the fast degradation of FeNC material under fuel cell operations.

On the other hand, from the standpoint of $\mathrm{Pt}$, the atomic proximity of single $\mathrm{M}-\mathrm{N}_{\mathrm{x}}$ sites improved the performance of the hybrid Pt/MNC catalyst due to a number of reasons: first, theoretical calculations indicated that compared to undoped pure graphene, there existed a tighter binding and shorter distance between MNC and Pt surface. ${ }^{18,33}$ This not only enhanced the interaction between Pt and MNC support, mitigating the agglomeration or detachment of Pt nanoparticles during operating conditions, but also lowered the barrier for charge transfer and hydrogen peroxide migration from MNC to Pt, thus facilitating the synergistic catalysis. Besides, $\mathrm{FeN}_{4}$ sites close to Pt could weaken the binding energy of 0 * on $\mathrm{Pt}(111)$ by $0.15 \mathrm{eV}$, approaching to the volcano peak $(0.20 \mathrm{eV})$, therefore improving the intrinsic activity of $\mathrm{Pt}^{33}$ Furthermore, densely and uniformly distributed ORR-active single $\mathrm{MN}_{4}$ (mostly $\mathrm{M}=\mathrm{Fe}$ and $\mathrm{Co}$ ) sites on the surface of the MNC support could contribute to the overall apparent activity through two parallel reaction pathways, two- and four-electron process. ${ }^{18,34,35}$ Besides the direct contribution through fourelectron reaction pathway, in two-electron reaction pathway, one so-called tandem catalysis mechanism, that is incomplete conversion of $\mathrm{O}_{2}$ into $\mathrm{H}_{2} \mathrm{O}_{2}$ and subsequent migration of $\mathrm{H}_{2} \mathrm{O}_{2}$ into adjacent Pt sites, is proposed. ${ }^{18,23}$

Due to the weak $\mathrm{O}^{*}$ adsorption energy on single Ni site, ${ }^{34,35}$ ORR-inactive NiNC catalysts, compared to their Fe and Co counterparts, have had a lower priority for the hybrid ORR catalyst design concept. However, NiNC supports offer other unexpected advantages that were previously overlooked. Despite its intrinsically poor ORR activity, NiNC provide other important benefits, including Fenton-inactive character and homogeneous distribution of ionomer benefiting from its N-doped feature ${ }^{6}$ (see Supplementary Discussions 4 and 5 for more details). On the other hand, although surface $\mathrm{NiN}_{\mathrm{x}}$ site motifs are not ORRactive, alloying Pt NPs with Ni into PtNi nanoalloys has resulted in the most reactive and highestperforming PEMFC ORR cathode catalysts to date. ${ }^{9,36}$ This bears the important and to-date untested hypothesis whether NiNC catalysts with its highly dispersed Ni atoms both in bulk and on surface may offer unique advantages in terms of the supply of individual $\mathrm{Ni}$ atoms during the formation of ORR-active and highly dispersed PtNi alloy NPs. In fact, other than $\mathrm{NiN}_{\mathrm{x}}$ sites, metallic Ni nanoparticulate agglomerates are often present in the bulk of NiNC catalysts due to high-temperature pyrolysis involved during the preparation of NiNC catalysts. Thus, hypothetically, thermally treating a hybrid Pt/NiNC catalyst, consisting of Pt NPs supported on NiNC support, we may be able to trigger the Pt-Ni particle alloying process, such that the $\mathrm{Ni}$ atoms are homogeneously supplied by either $\mathrm{NiN}_{\mathrm{x}}$ sites or $\mathrm{Ni} \mathrm{NPs} \mathrm{inside}$ the catalyst itself. Compared to conventional Ni impregnation/reduction pathways towards nanoalloy particles, the distribution of the initial Ni atom source would be much more homogeneous. The viability of this unusual PtNi alloy NP formation process, and the unambiguous identification of the atomic Ni 
source has never been considered before. This present study aims to change that by using in-situ transmission electron microscopy (TEM) technique to unravel the atomic process during the formation of the PtNi nanoalloy particles from pristine Pt/NiNC hybrid material and demonstrating the formation of highly active ORR electrocatalysts.

In this study, we investigate, validate and provide atomic insight into the hypothesized new synthetic pathway of ultralow PGM-loaded PtNi alloy NPs supported on NiNC material (referred to as a four-step PLDA process, see Fig. 1). Using in situ heating TEM and electrochemical $\mathrm{CO}$ ad/desorption techniques, we demonstrate that the highly dispersed metallic Ni NPs, rather than single $\mathrm{NiN}_{\mathrm{x}}$ sites, act as the supplying entity of individual $\mathrm{Ni}$ atoms for the formation of catalytically active, low-Pt loaded (3-5 wt\%), and uniform sized PtNi NPs. Subsequent electrochemical measurements via thin film rotating disk electrode (TF-RDE) method show that our resultant PtNi/NiNC catalysts, in spite of their low Pt-loaded (3-5 wt\%) feature, exhibit comparable or even higher ORR mass activities than C-supported, 20-30 wt\% Pt-loaded benchmark PtNi alloy catalysts, which would show great promise for future use in PEMFC cathodes.

\section{Results}

Synthetic design of catalyst. Fig. 1 and Supplementary Figs. 1, 2 illustrate the overall synthetic strategy of low-Pt PtNi alloy NPs supported on Ni- and N-doped carbon (NiNC) support. First, NiNC support was prepared via pyrolysis of a nickel coordination polymer (NCP) precursor [nickel(II) bisimidazolate, a$\left.\mathrm{Ni}(\mathrm{Im})_{2}\right]^{37}$ and subsequent acid leaching to remove partial metallic Ni particles (Steps $\mathbf{a}$ and $\mathbf{b}$ in Fig. 1). Then Pt NPs were deposited onto NiNC support at very low weight loading ( 3 wt\%) via facile polyol process, resulting in the pristine Pt/NiNC hybrid catalyst (Step $\mathbf{c}$ in Fig. 1). To form the final active low-Pt PtNi nanoalloy catalyst, the pristine Pt/NiNC hybrid catalyst was subjected to a second annealing treatment in $4 \% \mathrm{H}_{2} / \mathrm{Ar}$ (Step d in Fig. 1).

Sustainable synthesis of low-Pt PtNi/NiNC catalysts. As demonstrated in Supplementary Fig. 2e, our present PEMFC cathode catalyst synthetic method was easily scalable and was able to supply reproducible catalyst material at gram-scale from one single batch synthesis (see Supplementary Discussion 1 for more details). We note that the present synthesis involves inexpensive metal precursors, such as metal nitrates and chlorides, rather than expensive, unstable and toxic organometallic compounds, such as metal acetylacetonates or carbonyls. Direct and in situ deposition of Pt NPs onto support material was achieved via simple and facile polyol process. ${ }^{6,38,39}$ Unlike many other liquid-phase synthetic approaches generally carried out in either hydrophobic [oleylamine (OAm), octadecene (ODE), oleic acid (OA) or benzyl ether] or hydrophilic [dimethyl formamide (DMF)] solvents, the current ethylene glycol (EG) polyol route is rather sustainable and "green". ${ }^{39}$ This mainly results from two reasons: first, the coordinating/chelating properties of polar EG molecule are sufficient to functionalize and stabilize Pt NPs, which avoid the use of additional capping agent, and therefore circumvent the inherently complicated removal of surfactant molecules (OAm, OA or PVP) from the surface of Pt NPs before 
practical catalytic application. The weak interaction between EG and Pt NP and water solubility of EG allowed a simple water wash to easily clean the Pt NP surface. Second, the reducing power of EG at elevated temperatures makes additional reducing agent dispensable.

\section{Powder X-ray diffraction (XRD) and X-ray photoelectron spectroscopy (XPS) analysis. XRD patterns in}

Fig. 2a reveal structural characteristics of the synthetic intermediates: after pyrolysis and acid leaching, NiNC support demonstrates highly graphitized carbon as well as metallic Ni phases. This NiNC material served as support for the deposition of Pt NPs with 3 wt\% loading. The Pt/NiNC hybrid material featured a characteristic broad Pt(111) Bragg reflection, marked by blue arrow in Fig. 2a. After further annealing treatment applied to induce the PtNi alloy formation, the (111) diffraction peak moved in between those of monometallic Pt and Ni. According to Vegard's linear rule applied to the lattice parameter of facecentered cubic (fcc) PtNi solid solution alloy (Supplementary Fig. 3), ${ }^{40,41}$ the shift of the (111) reflection toward higher 2-Theta degree implied a decrease in the cubic unit cell parameter, indicating the successful incorporation of Ni atoms into the Pt NP lattices, forming PtNi alloy NPs. This observation was further confirmed by X-ray photoelectron spectroscopy (XPS) results (see more details in Supplementary Figs. 4-7 and Supplementary Tables 1-3). By normalizing the total integral areas of $\mathrm{Ni}$ $2 p$ and $\mathrm{Pt} 4 \mathrm{f}$ regions to their corresponding relative sensitivity factors (RSFs), we could obtain the Ni/Pt atomic ratio from XPS spectra (Fig. 2b, Supplementary Fig. 7 and Supplementary Tables 3). With increasing the annealing time, the XPS-derived experimental Ni/Pt atomic ratio increased from initial 0.2 in the pristine unannealed Pt/NiNC and gradually up to 0.77 in the final PtNi/NiNC alloy catalyst (with an annealing time of $6 \mathrm{~h}$ ). Given the conservation of $\mathrm{Ni}$ and $\mathrm{Pt}$ in the overall sample, this appears counterintuitive, however, can be rationalized based on the supply of Ni metal atoms from XPS-invisible metallic Ni NPs encapsulated by thick carbon layers. To show this, we also prepared Ni-free Vulcan carbon-supported Pt NP catalyst (referred to as Pt/Vul-C) using the identical procedure as for Pt/NiNC. The comparison with $\mathrm{Pt} / \mathrm{Vul}-\mathrm{C}$ allowed the unambiguous assignment of $\mathrm{Ni} 2 \mathrm{p}$ core level peaks of $\mathrm{Pt} / \mathrm{NiNC}$ to $\mathrm{N}$-coordinated single $\mathrm{Ni}$ atomic sites on the surface (Fig. 2c). The experimental increase in $\mathrm{Ni} / \mathrm{Pt}$ atomic ratio during and after the thermal annealing of the Pt/NiNC suggested that Ni species diffused across the carbon encapsulation and participated in the PtNi alloying process. XPS spectra in Fig. $2 \mathrm{~d}$ showed that upon annealing treatment, $\mathrm{Pt} 4 \mathrm{f}$ peaks shifted to lower binding energy, indicative of charge transfer from $\mathrm{Ni}$ to Pt due to the formation of the binary alloy phase. Hence, we hypothesize that the Ni atoms in the final PtNi alloy NPs derive to a large portion from the Ni NPs present in the NiNC support. To test our hypothesis, we use in situ heating TEM technique, which permits investigation of the evolution of our catalyst material during heating treatment. ${ }^{42-44}$

In situ thermal TEM analysis. A customized in situ heating TEM chip setup enabled us to design experiments to directly track the structural and morphological changes of the Pt/NiNC catalyst during thermal annealing (see Fig. 3 and Supplementary Video 1). We selected one specific field of view, in which smaller Pt and larger Ni NPs coexist, and simultaneously followed their morphological evolution during a stepwise thermal annealing from $25^{\circ} \mathrm{C}$ to $700^{\circ} \mathrm{C}$ (Fig. 3a). Thanks to their varying particle size, visual distinction between Pt and Ni NPs was obvious. Starting from $200{ }^{\circ} \mathrm{C}$, the temperature was held 
constant for $3 \mathrm{~min}$ at $100{ }^{\circ} \mathrm{C}$ increments, whereas it was held constant for $15 \mathrm{~min}$ at the final temperature of $700{ }^{\circ} \mathrm{C}$. Up to $500^{\circ} \mathrm{C}$, compared with the initial state (Fig. 3b), no significant changes in morphology were observed (Fig. 3c). Only the smallest observable Pt NPs (yellow circles in Fig. 3b, c and Supplementary Fig. 8) showed slight agglomeration or rounding. The critical temperature threshold, where Ni NPs started to change their morphology drastically was between 500 and $600{ }^{\circ} \mathrm{C}$. At $600{ }^{\circ} \mathrm{C}$, the TEM analysis revealed that individual Ni NPs shrank in size and gradually vanished. Figure $3 \mathrm{~d}$ evidences five Ni NPs marked by red arrows. Numbered from left to right, the first and fourth Ni NPs disappeared, whereas the others shrank. This observation suggested that $\mathrm{Ni}$ atoms started to diffuse across the carbon bulk to nearby regions and adjacent Pt NPs. The mobile Ni atoms were incorporated into Pt NPs to yield bimetallic PtNi alloy NPs. Direct evidence of this process is provided in Fig. $3 d-g$ (light green arrows), where one Ni NP first shrank in size before it performed a random walk to coalesce with nearby Pt NPs into a larger bimetallic PtNi alloy NP. Further holding at $700^{\circ} \mathrm{C}$ up to $15 \mathrm{~min}$ did not lead to any further changes (Supplementary Fig. 9). Besides, careful reference experiments were carried out to ensure the absence of any beam damage effect. Details on these experiments and conclusions are provided in the Supplementary Discussion 2.

Additional evidence of the key role of the large Ni NPs as atomic Ni source for the formation of the PtNi alloy NPs was provided from separate ex situ STEM/EDX as well as in situ heating TEM experiment (see Supplementary Discussion 3 and Supplementary Figs. 11-19), in which a Ni NP-free NiNC material (1 wt\% of Ni, thus referred to as "NiNC-1") served as catalyst support. Deposition of Pt NPs resulted in the Pt/NiNC-1 catalyst material. STEM-EDX analysis of Pt/NiNC-1 material (Supplementary Figs.14 and 15) showed carbon-embedded single Ni atom sites next to small Pt NPs before and after thermal annealing. In situ heating TEM studies analogous to those mentioned above confirmed both the absence of Ni NPs and the thermal stability of the supported Pt NPs (Supplementary Fig. 16 and Supplementary Video 2). There was no experimental evidence for the formation of bimetallic PtNi alloy NPs. Thus, we conclude that the $\mathrm{N}$-coordinated singe $\mathrm{Ni}$ atom sites, $\mathrm{NiN}_{\mathrm{x}}$ embedded in the carbon matrix of the NiNC-1 support were not released to form bimetallic alloys with the deposited Pt NPs.

Surface voltammetry and CO-stripping. To verify the successful formation of the final bimetallic PtNi alloy NP from the individual carbon-encapsulated Ni NP upon thermal annealing, we carried out voltammetric surface $\mathrm{CO}$ stripping (electrooxidation to $\mathrm{CO}_{2}$ ) as well as cyclic voltammetry (CV) to rather anodic potential of $1.6 \mathrm{~V}_{\mathrm{RHE}}$ (RHE, reversible hydrogen electrode), both in alkaline electrolyte. CO stripping voltammetry in alkaline solutions is one of the most surface-sensitive techniques to probe the presence of $\mathrm{Ni}$ atoms in or near the surface of Pt alloy catalysts. ${ }^{45-49}$ Prior to $\mathrm{CO}$ stripping in alkaline solution, the powder catalyst films were pretreated in acidic solution and thoroughly rinsed thereafter. Two potential cycling pretreatment protocols (Fig. 4a and b) with distinct upper potential limit (UPL) were applied. The pretreatment UPL prior to $\mathrm{CO}$ stripping tests was set to $0.6 \mathrm{~V}_{\mathrm{RHE}}$, whereas the UPL of CV tests was 0.925 $\mathrm{V}_{\mathrm{RHE}}$. The reason why we employ a more cathodic UPL for $\mathrm{CO}$ stripping was to prevent the formation of Pt oxides, which would affect the evolution of surface composition. ${ }^{50}$ Lower CO mobility in alkaline electrolyte than in acidic electrolyte results in multiple peaks, which result from the contributions of $\mathrm{Pt}$ 
surface sites with different activity toward $\mathrm{CO}$ oxidation. ${ }^{50-54}$ This offers us the ability to distinguish the Pt surface sites under different chemical environment. ${ }^{55} \mathrm{Fig} .4 \mathrm{c}$ shows background-subtracted $\mathrm{CO}$ stripping voltammograms of a series of as-annealed PtNi/NiNC catalysts after acidic pretreatment involving varying numbers of potential cycles. The current was normalized to the real Pt surface area obtained from the $\mathrm{CO}$ stripping peak area. The voltammetric $\mathrm{CO}$ stripping in Fig. 4c involves two redox waves: first, a more cathodic wave, labelled "Ni", at 0.4-0.5 $\mathrm{V}_{\mathrm{RHE}}$ that corresponds to electrooxidation of $\mathrm{CO}$ on Pt sites in proximity to surface $\mathrm{Ni}$ sites, and a more anodic stripping peak, labelled "Pt", at around $0.7 \mathrm{~V}_{\mathrm{RHE}}$ corresponding to $\mathrm{CO}$ oxidation at $\mathrm{Pt}$ site ensembles. Monotonic trends in " $\mathrm{Pt}$ " and "Ni" peak areas evidenced a gradual surface $\mathrm{Ni}$ dissolution with increasing acidic cycle numbers: the "Ni" $\mathrm{CO}$ stripping charge decreased, whereas the "Pt" CO stripping charge increased. CV scans of a series of asannealed PtNi/NiNC catalysts in $0.1 \mathrm{M} \mathrm{KOH}$ (Fig. 4d) exhibited the characteristic $\mathrm{Ni}^{2+} / \mathrm{Ni}^{3+}$ redox waves suggesting the presence of $\mathrm{Ni}$ atoms in the alloy NPs.

By contrast, when increasing the cycle numbers during acidic pretreatment of the pristine non-annealed $\mathrm{Pt} / \mathrm{NiNC}$ material, there was no discernible "Ni" CO stripping peak nor a Ni redox wave in the CV (Fig. 4e and f), evidencing absence of $\mathrm{Ni}$ atoms on the Pt surface. In Fig. 4e, the pristine non-annealed Pt/NiNC material showed the familiar main $\mathrm{CO}$ oxidation wave at $0.7 \mathrm{~V}_{\mathrm{RHE}}$ (labelled as "Pt1"), followed by a second one at around $0.8 \mathrm{~V}_{\mathrm{RHE}}$ (labelled as "Pt2"). From these voltammetric results, we conclude that the thermal treatment of the Pt/NiNC precursor material resulted in bimetallic PtNi alloy phases in the final $\mathrm{PtNi} / \mathrm{NiNC}$ catalyst.

To provide further independent evidence that encapsulated Ni NPs serve exclusively as the Ni atomic source for the formation of PtNi alloy NP, CO stripping and surface voltammetry were carried out using the Ni NP-free reference catalyst material, Pt/NiNC-1, as mentioned earlier (see Supplementary Figs. 1119 for more details of synthesis and characterization, and Supplementary Discussion 3 for conclusions). These results in alkaline electrolyte (Supplementary Fig. 19a and b) revealed the absence of both "Ni"type $\mathrm{CO}$ oxidation waves and $\mathrm{Ni}^{2+} / \mathrm{Ni}^{3+}$ redox peaks, respectively. Hence, the Pt NPs after thermal annealing remained $\mathrm{Ni}$-free. From this, we conclude that $\mathrm{N}$-coordinated single $\mathrm{Ni}$ atom centers, $\mathrm{NiN}_{\mathrm{x}}$, are unable to supply $\mathrm{Ni}$ atoms to form the PtNi alloy phase, which confirms that metallic carbonencapsulated Ni NPs must act as the main source of Ni species in the process of alloy formation.

Besides, to demonstrate the general applicability of our PLDA synthetic strategy to generate active PtNi alloy catalyst even at somewhat higher than $3 \mathrm{wt} \%$ Pt loading (Fig. 2, 3 and 4), we then prepare a 5 wt\% Pt-loaded catalyst materials (Supplementary Figs. 20-22), herein denoted as 5-Pt/NiNC and 5-PtNi/NiNC, respectively.

Electrocatalytic oxygen reduction reaction (ORR) activity. To evaluate the electrocatalytic ORR reactivity of the PtNi/NiNC electrocatalysts, we performed thin film-rotating disk electrode (TF-RDE) experiments (Fig. 5) ${ }^{56,57}$ Fig. 5a shows the initial cyclic voltammograms (CV) in $\mathrm{N}_{2}$-saturated electrolyte. As indicated by black arrows, after annealing, both $\mathrm{H}_{\mathrm{upd}}$ adsorption and desorption regions become smaller. This 
results from a NP growth along with the formation of PtNi alloy NPs with (sub)surface Ni atoms, which is known to partially suppress $\mathrm{H}_{\text {upd }}$ surface adsorption. ${ }^{9,17,58}$ To evaluate the catalytic ORR reactivity, linear sweep voltammetry (LSV) in $\mathrm{O}_{2}$-saturated electrolyte was conducted. The LSV polarization curves in Fig. $5 \mathrm{~b}$ showed a kinetic improvement in ORR activity over the pristine unannealed catalysts. Pt mass activities (MA) and specific activities (SA) were calculated by using the Koutecky-Levich formalism and subsequent normalization by Pt mass loadings and Pt surface area, respectively. As seen in Fig. $5 \mathrm{c}$, the $\mathrm{MA}$ and SA values of PtNi/NiNC catalyst at $0.9 \mathrm{~V}_{\mathrm{RHE}}$ exhibit improvement factors of $4.4 \times$ and $5.9 \times$, respectively, compared with pristine Pt/NiNC catalyst. And for 5-PtNi/NiNC catalyst, its MA and SA values increased improved by 5.5- and 7.2-fold, respectively. For comparison with commercial PtNi ORR fuel cell electrocatalysts, two dealloyed PtNi benchmark catalysts supplied from Johnson Matthey Fuel Cell (JMFC) and Umicore (Supplementary Figs. 23 and 24) were also measured.

The evaluation of the intrinsic specific ORR activity, that is, the reactivity based on the real surface area, care had to be taken: as seen in Fig. 5a, due to the relatively low content of Pt in these catalyst materials, combined with the partially suppressed sorption of $\mathrm{H}_{\text {upd }}$ on PtNi alloy surface, the $\mathrm{H}_{\text {upd }}$ sorption features between 0.05 and $0.4 \mathrm{~V}_{\mathrm{RHE}}$ are expectedly very weak. ${ }^{17,58}$ This, however, can lead to a large experimental error in the evaluation of the $\mathrm{H}_{\text {upd }}$ charge $\left(\mathrm{Q}_{\mathrm{H}}\right)$, the ECSA, and ultimately an inaccurate overestimation of intrinsic ORR activities. ${ }^{59}$ Thus, we employed $\mathrm{CO}$ stripping voltammetry, rather than $\mathrm{H}_{\text {upd }}$ method in this report to calculate the real Pt surface area. Background-subtracted $\mathrm{CO}$ stripping curves in Fig. $5 \mathrm{~d}$ shows that after annealing treatment, on one hand, the Pt surface area drops due to the agglomeration of $\mathrm{Pt}$ $\mathrm{NPs}$, on the other hand, the $\mathrm{CO}$ oxidation peak shifts toward lower potential, indicating that the formation of PtNi alloy phase modifies the electronic structure of $\mathrm{Pt}$ and promotes the $\mathrm{CO}$ electrooxidation performance. ${ }^{1,15,55,59,60}$

Transformation from Pt into PtNi alloy phase is further confirmed by the increase of the CO-ECSA/ $\mathrm{H}_{\mathrm{upd}^{-}}$ ECSA ratio after annealing treatment, as marked by the red curved arrows in Fig. 5e. Despite the difficulty in determining the accurate $\mathrm{H}_{\text {upd }}$ charge due to low Pt loading, it is still interesting that the ratio of $\mathrm{CO}$ -

ECSA versus $\mathrm{H}_{\text {upd }}$-ECSA could provide indicative information about the alloy formation. ${ }^{9,17,58}$ For the sake of consistency and better comparison between different samples, the $\mathrm{H}_{\text {upd }}$ integral area was obtained by integrating the current in the same potential range $\left(0.05-0.4 \mathrm{~V}_{\mathrm{RHE}}\right)$.

Stability tests were performed by cycling the potential between 0.6 and $0.925 \mathrm{~V}_{\mathrm{RHE}}$ for 10000 potential cycles at a sweeping rate of $100 \mathrm{mV} / \mathrm{s}$. As shown in Fig. $5 \mathrm{f}$, after 10000 cycles, the MA and SA of $\mathrm{PtNi} / \mathrm{NiNC}$ catalyst show activity losses of $22 \%$ and $23 \%$, respectively. For $5 \mathrm{wt} \%$ Pt-loaded counterpart, MA and SA of 5-PtNi/NiNC catalyst, display much smaller activity losses of $4 \%$ and $8 \%$, respectively.

\section{Conclusions}

In this contribution, we presented a novel PLDA synthetic pathway toward highly ORR active NiNCsupported PtNi alloy nanocatalysts and demonstrated the scalability of this preparation route to the 
gram-scale. The key novelty lies in the leverage of C-encapsulated metallic Ni (Ni@C) NPs-present in the bulk of NiNC support material-as Ni atom supply for the formation of the PtNi alloy NPs. The high initial dispersion of the Ni NP, which is inherited from Ni-containing coordination polymer precursor, allows for a homogeneous supply of individual $\mathrm{Ni}$ atoms across the material for the PtNi alloy formation at the Pt NP sites. For the first time, we visually tracked the concomitant PtNi alloy particle formation and the disappearance of Ni@C NPs at the atomic scale using in situ heating TEM experiments. We observed how the Ni NPs shrank while the catalytic PtNi NPs grew on the support. To verify our microscopic findings, we also used electrochemical $\mathrm{CO}$ ad/desorption experiments to sensitively probe the presence of $\mathrm{Ni}$ atoms at the (sub)surface of the PtNi NPs. Using carefully chosen reference experiments, we demonstrated that the $\mathrm{NiN}_{\mathrm{x}}$ single sites did not supply any $\mathrm{Ni}$ atoms thanks for their compositional stability. RDE measurements showed that our highly active PtNi alloy electrocatalysts, albeit their 3-5 wt\% low-Pt loading, achieved comparable or even higher mass activities than conventional, C-supported, 20-30 wt\% Pt-loaded benchmark PtNi alloy catalysts. More generally, in addition to these Pt-based catalysts investigated in this work, we believe that the validity and generality of our new PLDA approach would allow us to prepare other noble metal-based bimetallic NPs for other energy-related electrochemical reactions.

\section{Declarations}

\section{Data availability}

The data supporting the findings of this study are available within this article and its Supplementary Information files, or from the corresponding author upon reasonable request.

\section{Acknowledgements}

Q.F. gratefully acknowledges the support from Alexander von Humboldt Foundation. We acknowledge Johnson Matthey Fuel Cell and Umicore for the supply of catalysts. P.S. and M.H. acknowledge financial support of this work by the Deutsche Forschungsgemeinschaft (DFG) in the projects STR 596/5-2 and HE 7192/1-2.

\section{Author contributions}

Q.F. conceived and designed the study, analyzed data and wrote the manuscript. Q.F. carried out the material synthesis, characterizations and electrochemical measurements. X.W. performed the in situ heating TEM experiments. M.K. conducted the XPS measurements. M.H. performed the HRTEM, HAADFSTEM and STEM-EDX characterizations. P.S. supervised this study. All authors read and commented on the manuscript. 


\section{Competing interests}

The authors declare no competing interests.

\section{Additional information}

Supplementary information is available for this paper at https://doi.org/XXXXXX.

Correspondence and requests for materials should be addressed to Q.F., or P.S.

Reprints and permissions information is available at www.nature.com/reprints.

\section{References}

1. Strasser, P. et al. Lattice-strain control of the activity in dealloyed core-shell fuel cell catalysts. Nat. Chem. 2, 454-460 (2010).

2. Steele, B. C. H., Heinzel, A. Materials for fuel-cell technologies. Nature 414, 345-352 (2001).

3. Kodama, K., Nagai, T., Kuwaki, A., Jinnouchi, R., Morimoto, Y. Challenges in applying highly active Pt-based nanostructured catalysts for oxygen reduction reactions to fuel cell vehicles. Nat. Nanotechnol. $16,140-147$ (2021).

4. Debe, M. K. Electrocatalyst approaches and challenges for automotive fuel cells. Nature 486, 4351 (2012).

5. Sievers, G. W. et al. Self-supported Pt-CoO networks combining high specific activity with high surface area for oxygen reduction. Nat. Mater. 20, 208-213 (2020).

6. Ott, S. et al. Ionomer distribution control in porous carbon-supported catalyst layers for high-power and low Pt-loaded proton exchange membrane fuel cells. Nat. Mater. 19, 77-85 (2019).

7. Debe, M. K. Tutorial on the Fundamental Characteristics and Practical Properties of Nanostructured Thin Film (NSTF) Catalysts. J. Electrochem. Soc. 160, F522-F534 (2013).

8. Kongkanand, A., Mathias, M. F. The Priority and Challenge of High-Power Performance of LowPlatinum Proton-Exchange Membrane Fuel Cells. J. Phys. Chem. Lett. 7, 1127-1137 (2016).

9. Stamenkovic, V. R. et al. Improved Oxygen Reduction Activity on Pt3Ni(111) via Increased Surface Site Availability. Science 315, 493-497 (2007).

10. Han, B. et al. Record activity and stability of dealloyed bimetallic catalysts for proton exchange membrane fuel cells. Energy Environ. Sci. 8, 258-266 (2015). 
11. Owejan, J. P., Owejan, J. E., Gu, W. Impact of Platinum Loading and Catalyst Layer Structure on PEMFC Performance. J. Electrochem. Soc. 160, F824-F833 (2013).

12. Stephens, I. E. L., Rossmeisl, J., Chorkendorff, I. Toward sustainable fuel cells. Science 354, 13781379 (2016).

13. Seh, Z. W. et al. Combining theory and experiment in electrocatalysis: Insights into materials design. Science 355, eaad4998 (2017).

14. Chattot, R. et al. Surface distortion as a unifying concept and descriptor in oxygen reduction reaction electrocatalysis. Nat. Mater. 17, 827-833 (2018).

15. Greeley, J. et al. Alloys of platinum and early transition metals as oxygen reduction electrocatalysts. Nat. Chem. 1, 552-556 (2009).

16. Kulkarni, A., Siahrostami, S., Patel, A., Nørskov, J. K. Understanding Catalytic Activity Trends in the Oxygen Reduction Reaction. Chem. Rev. 118, 2302-2312 (2018).

17. Chen, C. et al. Highly Crystalline Multimetallic Nanoframes with Three-Dimensional Electrocatalytic Surfaces. Science 343, 1339-1343 (2014).

18. Chong, L. et al. Ultralow-loading platinum-cobalt fuel cell catalysts derived from imidazolate frameworks. Science 362, 1276-1281 (2018).

19. Li, M. et al. Ultrafine jagged platinum nanowires enable ultrahigh mass activity for the oxygen reduction reaction. Science 354, 1414-1419 (2016).

20. Gasteiger, H. A., Kocha, S. S., Sompalli, B., Wagner, F. T. Activity benchmarks and requirements for Pt, Pt-alloy, and non-Pt oxygen reduction catalysts for PEMFCs. Appl. Catal. B: Environ. 56, 9-35 (2005).

21. Lopez-Haro, M. et al. Three-dimensional analysis of Nafion layers in fuel cell electrodes. Nat. Commun. 5, 5229 (2014).

22. Wang, D. et al. Structurally ordered intermetallic platinum-cobalt core-shell nanoparticles with enhanced activity and stability as oxygen reduction electrocatalysts. Nat. Mater. 12, 81-87 (2012).

23. Shen, $\mathrm{X}$. et al. Dual-Site Cascade Oxygen Reduction Mechanism on SnOx/Pt-Cu-Ni for Promoting Reaction Kinetics. J. Am. Chem. Soc. 141, 9463-9467 (2019).

24. Hernandez-Fernandez, P. et al. Mass-selected nanoparticles of PtxY as model catalysts for oxygen electroreduction. Nat. Chem. 6, 732-738 (2014).

25. Escudero-Escribano, M. et al. $\mathrm{Pt}_{5} \mathrm{Gd}$ as a Highly Active and Stable Catalyst for Oxygen Electroreduction. J. Am. Chem. Soc. 134, 16476-16479 (2012). 
26. Escudero-Escribano, M. et al. Tuning the activity of Pt alloy electrocatalysts by means of the lanthanide contraction. Science 352, 73-76 (2016).

27. Huang, $X$. et al. High-performance transition metal-doped $\mathrm{Pt}_{3} \mathrm{Ni}$ octahedra for oxygen reduction reaction. Science 348, 1230-1234 (2015).

28. Cui, C., Gan, L., Heggen, M., Rudi, S., Strasser, P. Compositional segregation in shaped Pt alloy nanoparticles and their structural behaviour during electrocatalysis. Nat. Mater. 12, 765-771 (2013).

29. Gan, L. et al. Element-specific anisotropic growth of shaped platinum alloy nanocrystals. Science 346, 1502-1506 (2014).

30. Shin, D. et al. Reduced formation of peroxide and radical species stabilises iron-based hybrid catalysts in polymer electrolyte membrane fuel cells. J. Energy Chem. 65, 433-438 (2022).

31. Kosmala, T. et al. Stable, Active, and Methanol-Tolerant PGM-Free Surfaces in an Acidic Medium: Electron Tunneling at Play in Pt/FeNC Hybrid Catalysts for Direct Methanol Fuel Cell Cathodes. ACS Catal. $10,7475-7485$ (2020).

32. Mechler, A. K. et al. Stabilization of Iron-Based Fuel Cell Catalysts by Non-Catalytic Platinum. J. Electrochem. Soc. 165, F1084-F1091 (2018).

33. Qiao, Z. et al. Atomically Dispersed Single Iron Sites for Promoting Pt and $\mathrm{Pt}_{3}$ Co Fuel Cell Catalysts: Performance and Durability Improvements. Energy Environ. Sci. 14, 4948-4960 (2021).

34. Luo, F. et al. P-block single-metal-site tin/nitrogen-doped carbon fuel cell cathode catalyst for oxygen reduction reaction. Nat. Mater. 19, 1215-1223 (2020).

35. Sun, Y. et al. Activity-Selectivity Trends in the Electrochemical Production of Hydrogen Peroxide over Single-Site Metal-Nitrogen-Carbon Catalysts. J. Am. Chem. Soc. 141, 12372-12381 (2019).

36. Sun, Y. et al. Advancements in Cathode Catalyst and Cathode Layer Design for Proton Exchange Membrane Fuel Cells. Nat. Commun. 12, DOI: 10.1038/s41467-41021-25911-x (2021).

37. Masciocchi, N., Castelli, F., Forster, P. M., Tafoya, M. M., Cheetham, A. K. Synthesis and Characterization of Two Polymorphic Crystalline Phases and an Amorphous Powder of Nickel(II) Bisimidazolate. Inorg. Chem. 42, 6147-6152 (2003).

38. Orfanidi, A. et al. The Key to High Performance Low Pt Loaded Electrodes. J. Electrochem. Soc. 164, F418-F426 (2017).

39. Dong, H., Chen, Y. C., Feldmann, C. Polyol synthesis of nanoparticles: status and options regarding metals, oxides, chalcogenides, and non-metal elements. Green Chem. 17, 4107-4132 (2015). 
40. Cullity, B. D., Stock, S. R. Elements of X ray diffraction, 3 edn. Prentice Hall: New York, 2001.

41. DeGraef, M., McHenry, M. E. Structure of Materials: An Introduction to Crystallography, Diffraction, and Symmetry. Cambrige University Press: Cambridge, 2007.

42. Gocyla, M. et al. Shape Stability of Octahedral PtNi Nanocatalysts for Electrochemical Oxygen Reduction Reaction Studied by in situ Transmission Electron Microscopy. ACS Nano 12, 5306-5311 (2018).

43. Beermann, V. et al. Real-time imaging of activation and degradation of carbon supported octahedral Pt-Ni alloy fuel cell catalysts at the nanoscale using in situ electrochemical liquid cell STEM. Energy Environ. Sci. 12, 2476-2485 (2019).

44. Wei, S. et al. Direct observation of noble metal nanoparticles transforming to thermally stable single atoms. Nat. Nanotechnol. 13, 856-861 (2018).

45. Rudi, S., Cui, C., Gan, L., Strasser, P. Comparative Study of the Electrocatalytically Active Surface Areas (ECSAs) of Pt Alloy Nanoparticles Evaluated by Hupd and CO-stripping voltammetry.

Electrocatalysis 5, 408-418 (2014).

46. Beermann, V., Kühl, S., Strasser, P. Tuning the Catalytic Oxygen Reduction Reaction Performance of Pt-Ni Octahedral Nanoparticles by Acid Treatments and Thermal Annealing. J. Electrochem. Soc. 165, J3026-J3030 (2018).

47. Rudi, S. et al. pH-Induced versus Oxygen-Induced Surface Enrichment and Segregation Effects in Pt-Ni Alloy Nanoparticle Fuel Cell Catalysts. ACS Catal. 7, 6376-6384 (2017).

48. Rudi, S., Gan, L., Cui, C., Gliech, M., Strasser, P. Electrochemical Dealloying of Bimetallic ORR Nanoparticle Catalysts at Constant Electrode Potentials. J. Electrochem. Soc. 162, F403-F409 (2015).

49. Beermann, V. et al. Tuning the Electrocatalytic Oxygen Reduction Reaction Activity and Stability of Shape-Controlled Pt-Ni Nanoparticles by Thermal Annealing - Elucidating the Surface Atomic Structural and Compositional Changes. J. Am. Chem. Soc. 139, 16536-16547 (2017).

50. Cui, C. et al. Shape-selected bimetallic nanoparticle electrocatalysts: evolution of their atomicscale structure, chemical composition, and electrochemical reactivity under various chemical environments. Faraday Discuss. 162, 91-112 (2013).

51. Spendelow, J. S., Lu, G. Q., Kenis, P. J. A., Wieckowski, A. Electrooxidation of adsorbed CO on $\mathrm{Pt}(111)$ and $\mathrm{Pt}(111) / \mathrm{Ru}$ in alkaline media and comparison with results from acidic media. J. Electroanal. Chem. 568, 215-224 (2004).

52. Spendelow, J. S., Goodpaster, J. D., Kenis, P. J. A., Wieckowski, A. Mechanism of CO Oxidation on Pt(111) in Alkaline Media. J. Phys. Chem. B 110, 9545-9555 (2006). 
53. García, G., Koper, M. T. M. Stripping voltammetry of carbon monoxide oxidation on stepped platinum single-crystal electrodes in alkaline solution. Phys. Chem. Chem. Phys. 10, 3802-3811 (2008).

54. Marković, N. M., Lucas, C. A., Rodes, A., Stamenković, V., Ross, P. N. Surface electrochemistry of CO on Pt(111): anion effects. Surf. Sci. 499, L149-L158 (2002).

55. Maillard, F. et al. Influence of particle agglomeration on the catalytic activity of carbon-supported Pt nanoparticles in CO monolayer oxidation. Phys. Chem. Chem. Phys. 7, 385-393 (2005).

56. Mayrhofer, K. J. J. et al. Measurement of oxygen reduction activities via the rotating disc electrode method: From Pt model surfaces to carbon-supported high surface area catalysts. Electrochim. Acta 53, 3181-3188 (2008).

57. Martens, S. et al. A comparison of rotating disc electrode, floating electrode technique and membrane electrode assembly measurements for catalyst testing. J. Power Sources 392, 274-284 (2018).

58. van der Vliet, D. F. et al. Unique Electrochemical Adsorption Properties of Pt-Skin Surfaces. Angew. Chem. Int. Ed. 51, 3139-3142 (2012).

59. Maillard, F. et al. Size effects on reactivity of Pt nanoparticles in CO monolayer oxidation: The role of surface mobility. Faraday Discuss. 125, 357-377 (2004).

60. Maillard, F., Savinova, E. R., Stimming, U. CO monolayer oxidation on Pt nanoparticles: Further insights into the particle size effects. J. Electroanal. Chem. 599, 221-232 (2007).

\section{Methods}

Synthesis of a-Ni(Im) $)_{2}$ precursor: Typically, $\mathrm{Ni}\left(\mathrm{NO}_{3}\right)_{2} \cdot 6 \mathrm{H}_{2} \mathrm{O}(30 \mathrm{mmol}, 8.724 \mathrm{~g})$ was dissolved in $600 \mathrm{~mL}$ deionized $\mathrm{H}_{2} \mathrm{O}$. Then, solid imidazole $(24 \mathrm{~g}, 352.5 \mathrm{mmol}$ ) was added to this aqueous solution. $\mathrm{NaOH}$ aqueous solution $(0.3 \mathrm{M}, 1200 \mathrm{~mL})$ was added dropwise at a rate of $60 \mathrm{~mL} \mathrm{~min}{ }^{-1}$. The flow rate was controlled by a peristaltic pump. The resulting suspension was filtered and washed with water and ethanol several times and dried in a heating oven overnight at $70^{\circ} \mathrm{C}$. The as-obtained yellow powder was $\mathrm{a}-\mathrm{Ni}(\mathrm{Im})_{2}$ precursor. $^{37}$

Synthesis of NiNC support material: $550 \mathrm{mg}$ of Vulcan carbon (XC72R) and $5.5 \mathrm{~g}$ of a-Ni(Im) $)_{2}$ were poured into a beaker which contained $1 \mathrm{~L}$ of water and $20 \mathrm{~mL}$ ethanol. The above suspension was vigorously stirred for $30 \mathrm{~min}$, followed by sonication in a water bath for another $30 \mathrm{~min}$. This agitationsonication process was cycled for several times until Vulcan carbon and $\mathrm{a}-\mathrm{Ni}(\mathrm{Im})_{2}$ were thoroughly and homogeneously mixed together. The solid mixture was filtered and dried in a freeze dryer. Pyrolysis of a$\mathrm{Ni}(\mathrm{Im})_{2}$ was directly carried out under a nitrogen flow at $900^{\circ} \mathrm{C}$ for $3 \mathrm{~h}$. The ramping rate from RT to 900 ${ }^{\circ} \mathrm{C}$ is $5^{\circ} \mathrm{C} \mathrm{min}{ }^{-1}$. The pyrolyzed sample was then soaked in excess dilute sulfuric acid $\left(\mathrm{H}_{2} \mathrm{SO}_{4}\right)$ solution 
$(0.2 \mathrm{M})$ at $70{ }^{\circ} \mathrm{C}$ for $12 \mathrm{~h}$ to remove the partially exposed Ni NPs. Then the product was centrifugated and washed with copious water and dried in a freeze dryer.

Preparation of the pristine Pt/NiNC catalysts: Herein, the as-obtained NiNC was used as support material for the deposition of ultralow amounts of Pt NPs. The functionalization of NiNC by Pt NPs was carried out via simple polyol process. ${ }^{6,38} 1800 \mathrm{mg}$ of NiNC was added into a $1000 \mathrm{~mL}$ round bottom flask which contained $300 \mathrm{~mL}$ of ethylene glycol and $150 \mathrm{~mL}$ of DI water. To obtained a homogeneous solution, the above suspension was sonicated in a water bath for $15 \mathrm{~min}$. Then $1854 \mu \mathrm{L}$ of $\mathrm{H}_{2} \mathrm{PtCl}_{6}$ solution (0.192 M) was added into the above solution and stirred vigorously at room temperature for $18 \mathrm{~h}$. To complete the reduction of the Pt precursor, the reaction flask was immersed in a $120^{\circ} \mathrm{C}$ pre-heated oil bath and stirred under reflux condition for $2 \mathrm{~h}$. The product was collected by centrifugation and washed with water/ethanol mixture for several times and dried in a freeze dryer. The actual Pt content was measured by ICP-OES.

For 5 wt\% Pt-loaded catalyst, $3159 \mu \mathrm{L}$ of $\mathrm{H}_{2} \mathrm{PtCl}_{6}$ precursor solution (0.192 M) was added while other parameters were kept same.

Preparation of PtNi/NiNC catalysts: The as-synthesized Pt/NiNC catalysts were annealed under $4 \% \mathrm{H}_{2} / \mathrm{Ar}$ at $700{ }^{\circ} \mathrm{C}$ for $6 \mathrm{~h}$. And the ramping rate from $\mathrm{RT}$ to $700{ }^{\circ} \mathrm{C}$ is $5^{\circ} \mathrm{C} \mathrm{min}^{-1}$.

In situ heating TEM study was performed at a FEI Tecnai G 20 S-TWIN transmission electron microscope with a $\mathrm{LaB}_{6}$ cathode operated at an accelerating voltage of $200 \mathrm{kV}$ (ZELMI Centrum, Technical University of Berlin). For in situ TEM experiments, a heating holder (DENS solutions B.V.) was applied. The catalyst powder was first dispersed into isopropanol solution with ultrasonication. Then this catalyst solution was drop cast onto a MEMS chip. The precise control of temperature was realized by four-point measurement integrated on the chip. After complete drying under ambient condition, the heating chip was mounted on a TEM holder.

CO stripping in $0.1 \mathrm{M} \mathrm{KOH}$ alkaline electrolyte: for $\mathrm{CO}$ stripping in alkaline electrolyte, electrochemical pretreatments in $0.1 \mathrm{M} \mathrm{HClO}_{4}$ acidic electrolyte were first performed. The potential was cycled between 0.05 and $0.6 \mathrm{~V}_{\mathrm{RHE}}$ at $100 \mathrm{mV} / \mathrm{s}$ in deaerated $0.1 \mathrm{M} \mathrm{HClO}_{4}$ acidic electrolyte. Catalyst that underwent different potential cycles in acidic electrolyte were denoted as "UL600acid-XXC". UL600 means that the upper potential limit during cycling is $600 \mathrm{mV}_{\mathrm{RHE}}$, and $\mathrm{XXC}$ denotes the actual number of potential cycles. After electrochemical pre-treatment in acidic solution, the electrode was rinsed by ultrapure water. CO stripping was then performed following the same procedure as described in the section of "CO stripping", except that $0.1 \mathrm{M} \mathrm{KOH}$ alkaline electrolyte was used.

CV in 0.1 M KOH alkaline electrolyte: for CV test in alkaline electrolyte, electrochemical pre-treatments in $0.1 \mathrm{M} \mathrm{HClO}_{4}$ acidic electrolyte were first performed. The potential was cycled between 0.05 and 0.925 $\mathrm{V}_{\mathrm{RHE}}$ at $100 \mathrm{mV} / \mathrm{s}$ in deaerated $0.1 \mathrm{M} \mathrm{HClO}_{4}$ acidic electrolyte. Catalyst that underwent different potential cycles in acidic electrolyte were denoted as "UL925acid-XXC". Herein, UL925 means that the upper 
potential limit during cycling is $925 \mathrm{mV}_{\mathrm{RHE}}$, and $\mathrm{XXC}$ denotes the actual number of potential cycles. After electrochemical pre-treatment in acidic solution, the electrode was rinsed by ultrapure water. CV was performed in $\mathrm{N}_{2}$-saturated $0.1 \mathrm{M} \mathrm{KOH}$ alkaline electrolyte between 0.05 and $1.6 \mathrm{~V}_{\mathrm{RHE}}$ at $100 \mathrm{mV} / \mathrm{s}$.

\section{Figures}

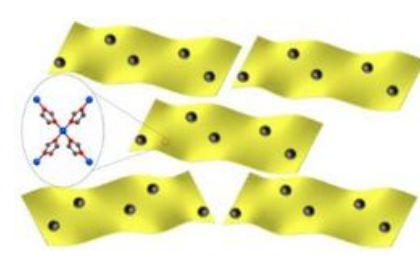

$\alpha-\mathrm{Ni}(\mathrm{Im})_{2}+\mathrm{Vul}-\mathrm{C}$ (a) Pyrolysis

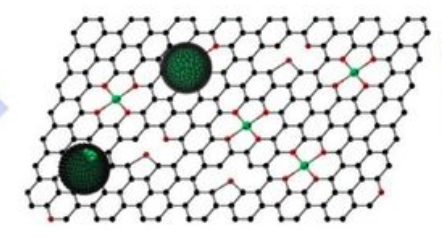

(b) Leaching

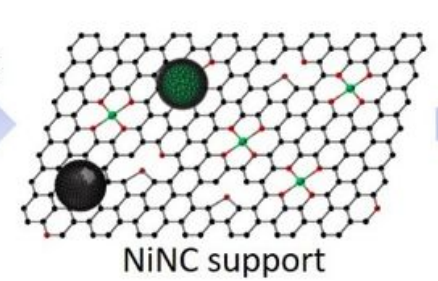

NiNC support

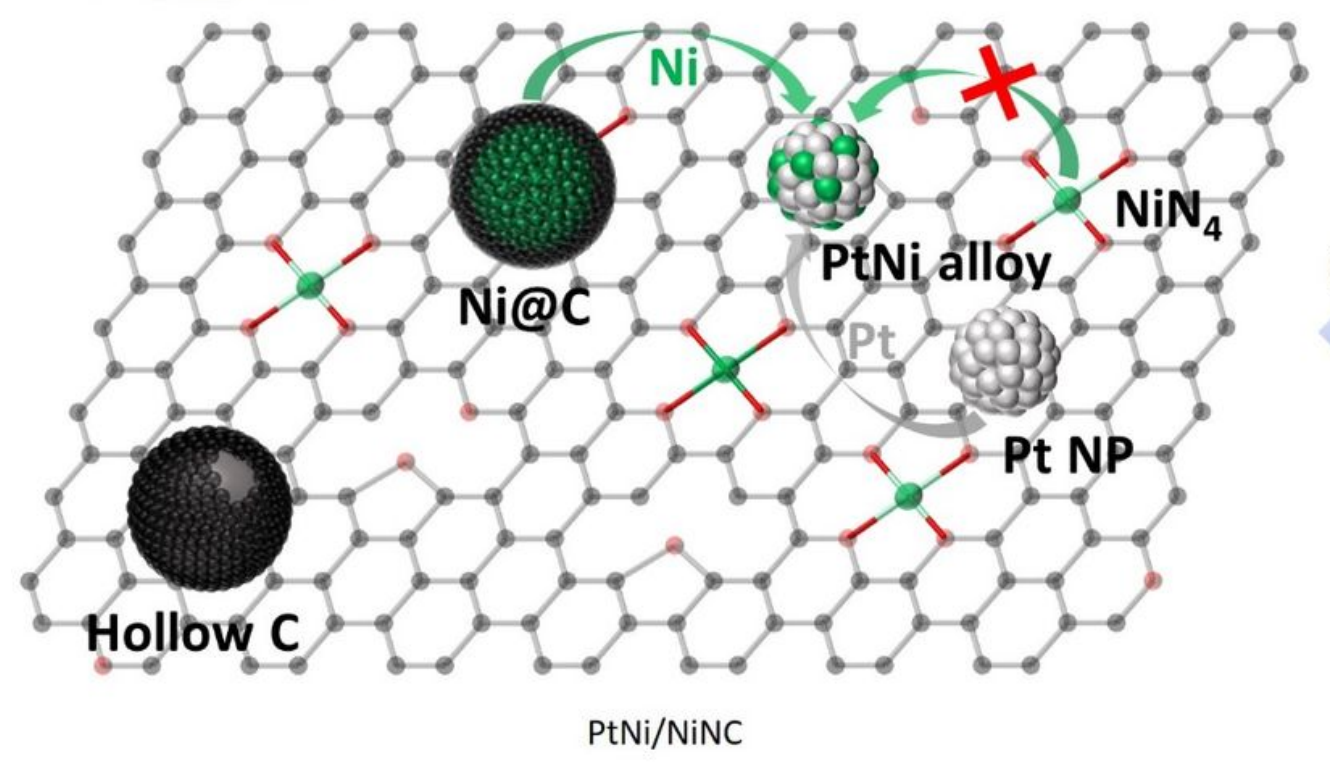

(d) Alloying

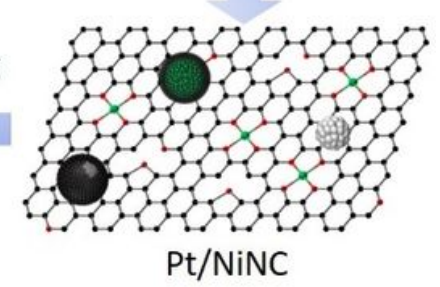

\section{Figure 1}

Schematic illustration of the pyrolysis-leaching-deposition-alloying (PLDA) strategy reported in this study. (a) Pyrolysis of homogeneous mixture of nickel coordination polymer (NCP) precursor, a-Ni(Im)2, and Vulcan carbon. During high-temperature pyrolysis, $\mathrm{Ni}$ cations in a-Ni( $(\mathrm{Im}) 2$ either were reduced to metallic Ni NPs, or were transformed to single NiNx sites. (b) Subsequent acid leaching to remove the partial unstable Ni NPs which were incompletely protected by the carbon shell, leaving a hollow carbon structure with an opening. Due to their acidic resistance, Ni NPs thoroughly covered by carbon shell, that was Ni@C structure, and single NiNx sites were left unchanged in this corrosive step. (c) In situ deposition of 3 wt\% Pt NPs onto NiNC support via simple polyol process. (d) Formation of PtNi alloy NP was triggered by thermal annealing treatment. In the enlarged inset, the green and grey arrows represented the supplying routes of $\mathrm{Ni}$ and $\mathrm{Pt}$ during alloying process, respectively, whereas one green arrow with red cross indicated that the supplying route of $\mathrm{Ni}$ from single NiNx sites was not viable. 

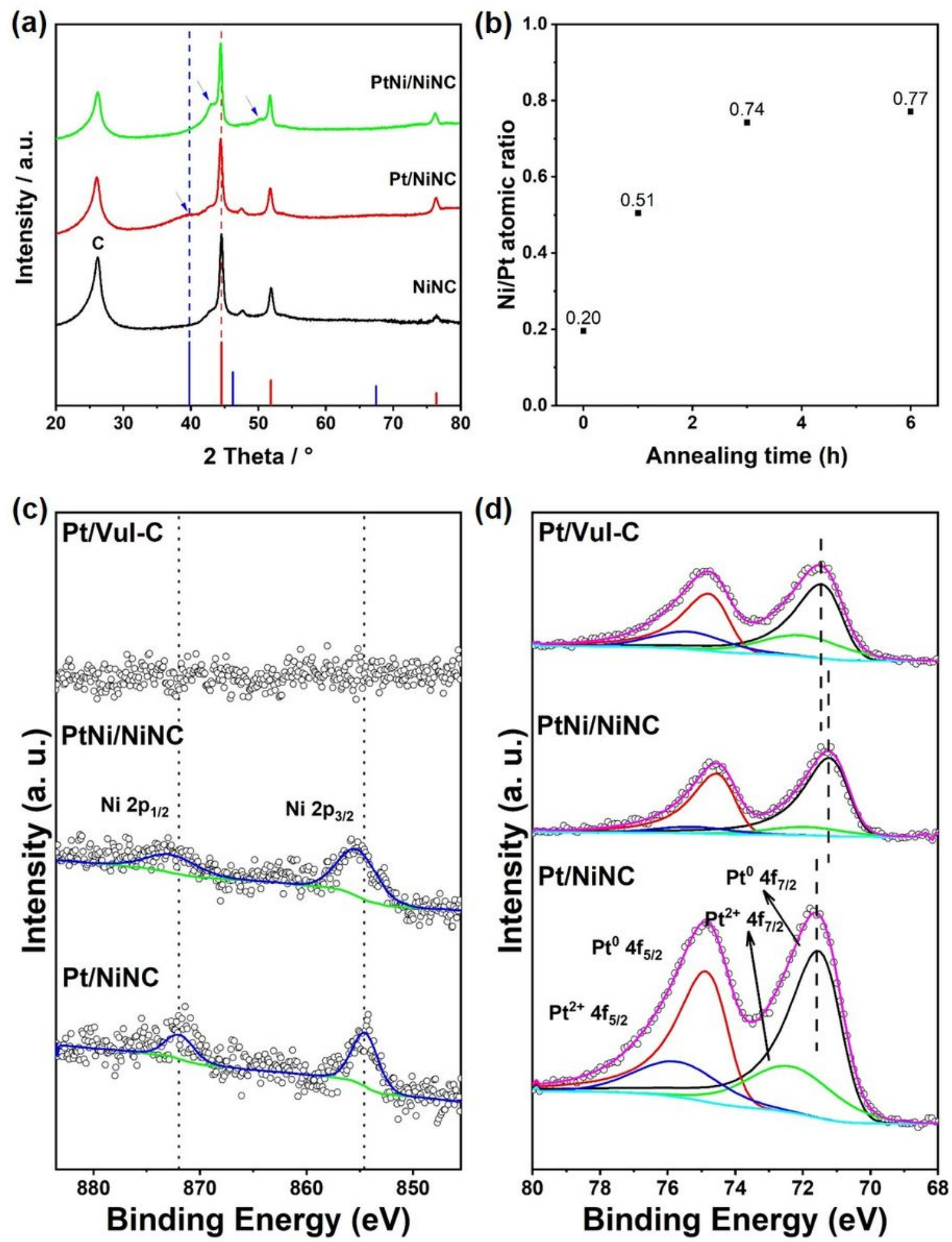

Figure 2

Chemical and structural characterizations of catalyst materials derived from Pt/NiNC before and after annealing treatment. (a) XRD patterns of NiNC support, pristine Pt/NiNC and as-annealed PtNi/NiNC materials. Blue arrows indicate the shift of Pt peaks before and after annealing treatment. Standard patterns of Pt (blue lines, PDF No. 00-004-0802) and Ni (red lines, PDF No. 99-000-2639) are also shown. (b) Change of $\mathrm{Ni} / \mathrm{Pt}$ atomic ratio versus the annealing time in hours. By normalizing the total integral 
areas of $\mathrm{Ni} 2 \mathrm{p}$ and $\mathrm{Pt} 4 \mathrm{f}$ regions to their corresponding relative sensitivity factors (RSFs), the Ni/Pt atomic ratios were obtained from XPS spectra. (c) Ni 2p and (d) Pt $4 f$ XPS spectra of pristine Pt/NiNC and asannealed PtNix/NiNC, together with Pt/Vul-C reference material. XPS fitting was carried out by using CASA XPS software. For Pt0 species, asymmetric line shape of $\operatorname{LA}(1.2,85,70)$ was used, whereas for $\mathrm{Pt} 2+$ species, line shape of GL (30) was chosen. These vertical dashed lines are present as a guide for eyes.
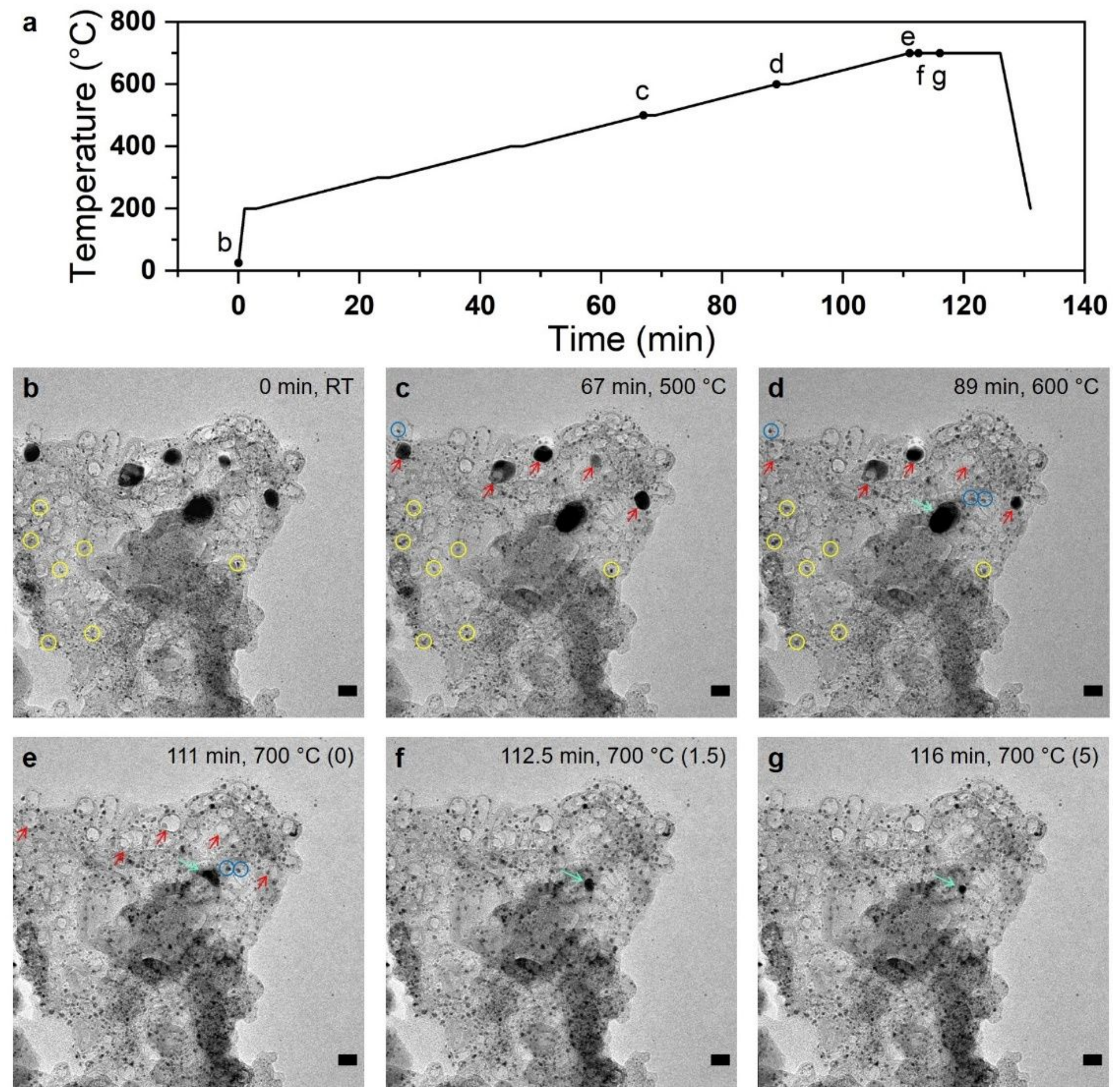

Figure 3 
Investigation of the evolution from Pt to PtNi alloy using an in situ heating TEM technique. In situ TEM imaging of the pristine hybrid Pt/NiNC catalyst during heating from $25^{\circ} \mathrm{C}(\mathrm{RT})$ to $700{ }^{\circ} \mathrm{C}$ under vacuum condition. (a) Temperature profile over time with marked points corresponding to the images in panels $\mathrm{b}-$ g. Starting from $200{ }^{\circ} \mathrm{C}$, temperature was increased in step of $100{ }^{\circ} \mathrm{C}(5 \mathrm{~K} / \mathrm{min})$. The specimen was annealed for $2 \mathrm{~min}$ at each step below $700^{\circ} \mathrm{C}$ and $15 \mathrm{~min}$ at final $700^{\circ} \mathrm{C}$. Yellow circles in panels $\mathrm{b}-\mathrm{d}$ mark the Pt NPs agglomerated. Red arrows in panels c-e mark the evolution of Ni NPs. Light green arrows in panels $\mathrm{d}-\mathrm{g}$ mark the same Ni NPs. In panels $\mathrm{e}-\mathrm{g}$, the numbers in parentheses indicate the holding time in minutes at $700{ }^{\circ} \mathrm{C}$. Scale bar: $20 \mathrm{~nm}$.

(a)
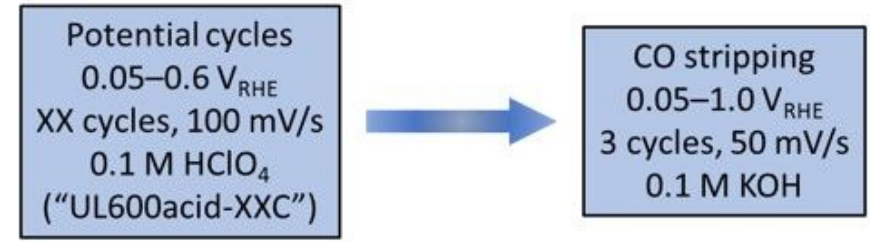

\section{(c)}
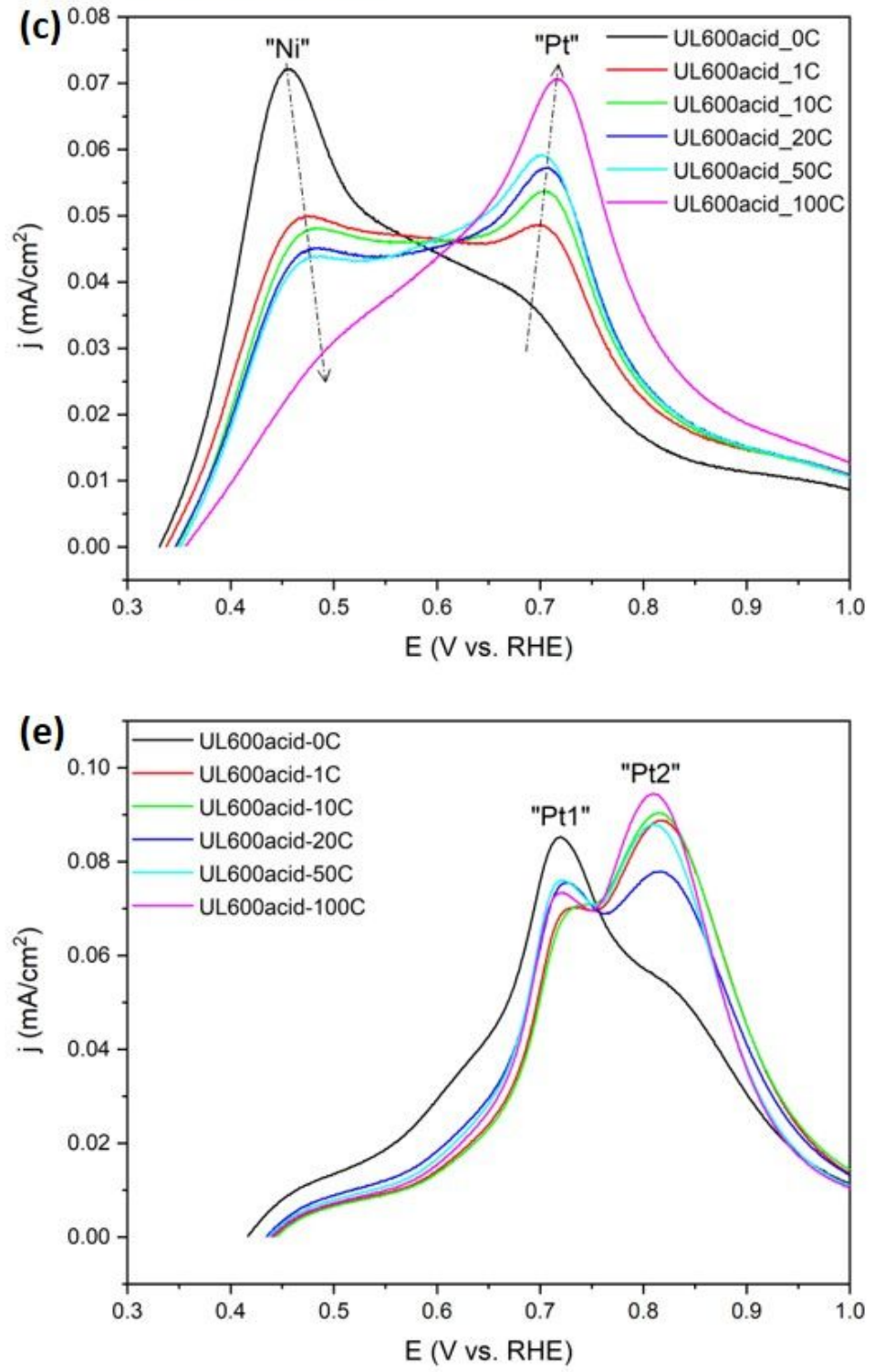

(b)
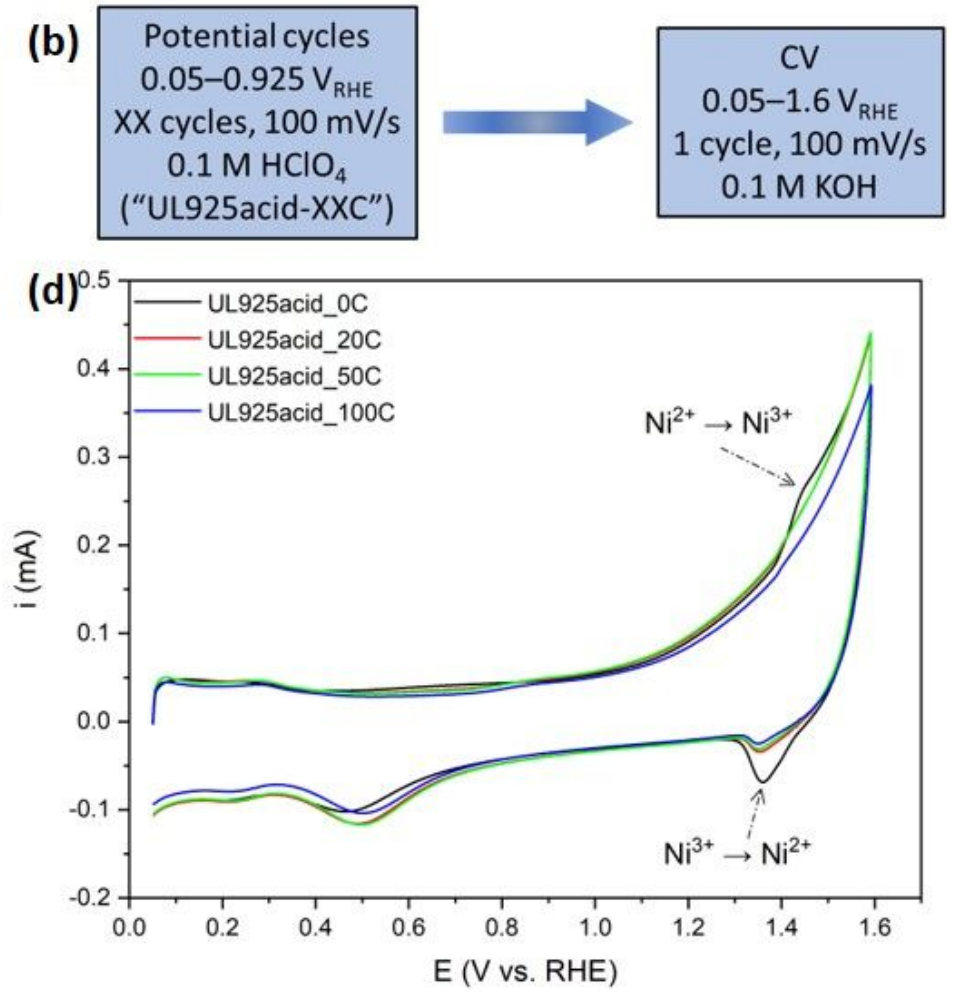

(f)

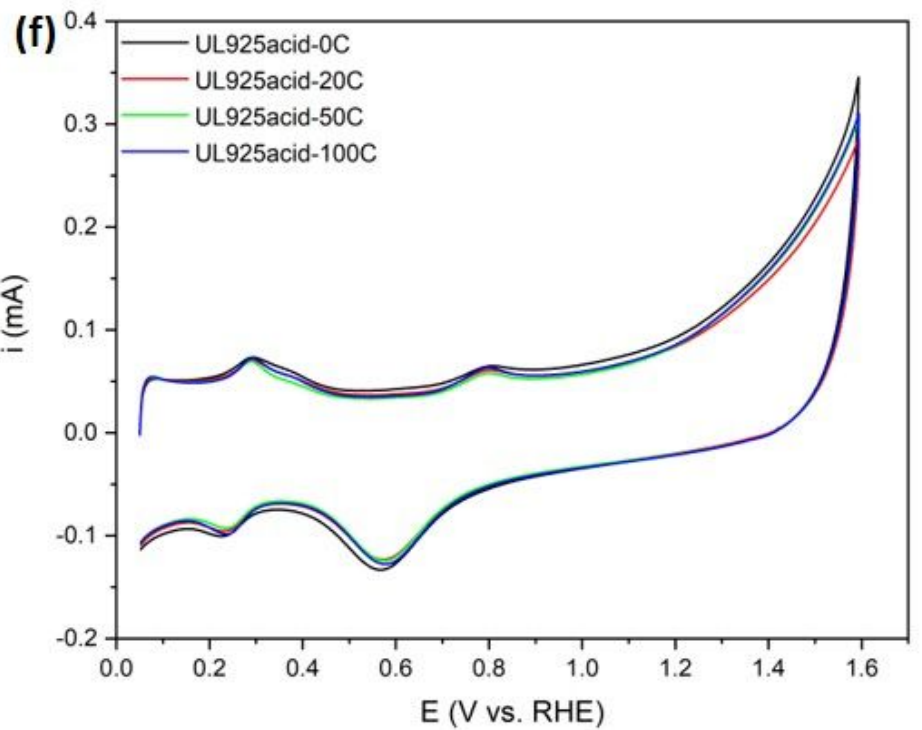

Figure 4 
Surface characterization by CO electrooxidation and CV measurements in alkaline electrolyte. (Left) Electrochemical pre-treatments in $0.1 \mathrm{M} \mathrm{HClO} 4$ acidic electrolyte and (right) subsequent measurements in $0.1 \mathrm{M} \mathrm{KOH}$ alkaline electrolyte for (a) CO electrooxidation and (b) CV measurements. (c, e) Pt surface area-normalized and background-subtracted $\mathrm{CO}$ stripping voltammetry and $(\mathrm{d}, \mathrm{f}) \mathrm{CV}$ curves in $0.1 \mathrm{M} \mathrm{KOH}$ solution for a series of catalyst films undergoing pretreatment in acidic solution with different potential cycling numbers: $(c, d)$ as-annealed PtNi/NiNC and $(e, f)$ pristine non-annealed Pt/NiNC samples, respectively.
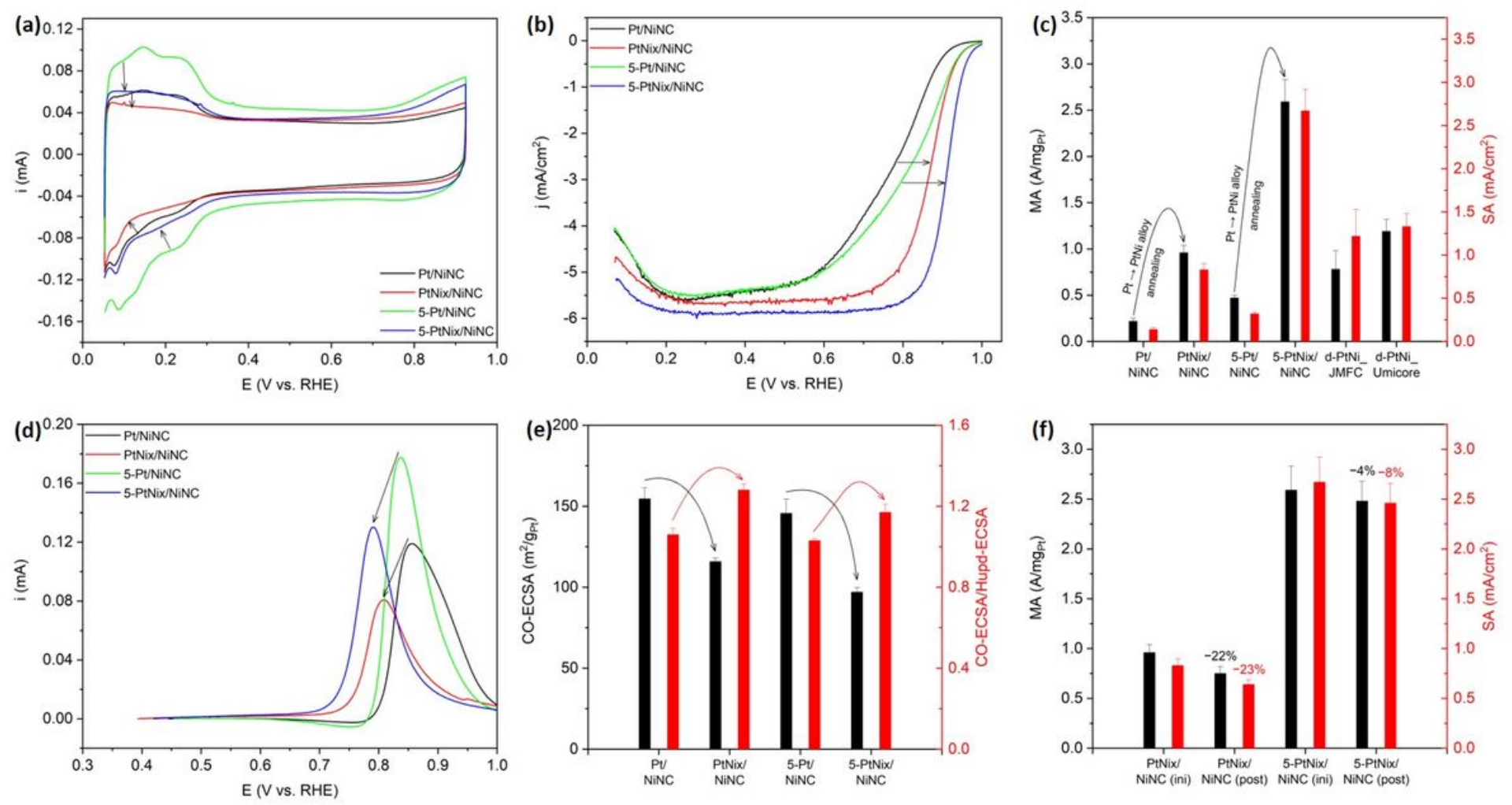

Figure 5

RDE electrochemical measurements on Pt/NiNC-based catalyst samples with two dealloyed PtNi alloy benchmark catalysts. (a) Cyclic voltammetry (CV) curves of pristine Pt/NiNC and as-annealed PtNi/NiNC catalyst samples. Black arrows indicate the decrease of Hupd regions. (b) ORR polarization curves. Black arrows indicate the right shift of half-wave potential. (c) Comparison of mass activities (MA) and specific activities (SA) measured at 0.9 VRHE. (d) Background-subtracted CO stripping voltammetry curves. Black arrows indicate the cathodic shift of the $\mathrm{CO}$ oxidation peak after annealing treatment. (e) CO-ECSA values estimated from CO stripping method and the ratios of CO-ECSA versus Hupd-ECSA. Black curved arrows indicate the decrease of CO-ECSA values, whereas red ones indicate the increase of the ratio of COECSA/Hupd-ECSA. (f) Comparison of MA and SA before and after the accelerated durability test (ADT), which is $10000 \mathrm{CV}$ cycles between 0.6 and $0.925 \mathrm{VRHE}$ at $100 \mathrm{mV} / \mathrm{s}$. Geometric Pt mass loading: 1.9 $\mu \mathrm{g} / \mathrm{cm} 2$ for Pt/NiNC, $1.9 \mu \mathrm{g} / \mathrm{cm} 2$ for PtNi/NiNC, $3.2 \mu \mathrm{g} / \mathrm{cm} 2$ for 5-Pt/NiNC, $3.2 \mu \mathrm{g} / \mathrm{cm} 2$ for 5-PtNi/NiNC, $14.7 \mu \mathrm{g} / \mathrm{cm} 2$ for d-PtNi_JMFC, and $14.9 \mu \mathrm{g} / \mathrm{cm} 2$ for d-PtNi_Umicore. 


\section{Supplementary Files}

This is a list of supplementary files associated with this preprint. Click to download.

- SubmittedESI.docx

- SupplementaryVideo1.mp4

- SupplementaryVideo2.avi 